\title{
Complex Effects of Hot and Cold Procedures on Skin Elasticity in Spa \& Wellness
}

\author{
Nevenka Panovska \\ Antoaneta Dimitrova, PhD
}

Department of Physiotherapy and Rehabilitation, National Sports Academy

"Vassil Levski", Sofia, Bulgaria

Doi: 10.19044/esj.2018.v14n6p1 URL:http://dx.doi.org/10.19044/esj.2018.v14n6p1

\begin{abstract}
The purpose of this study is to evaluate the complex effects of the hot and cold procedures, practiced in modern Spa \& Wellness, on skin elasticity, as that indicator is an integral factor defining the aesthetic vision of the skin. Material and Methods: The present study tracked 60 women aged 35 to 65 years. The methods included an aesthetic skin rejuvenation program that contained a complex of 12 Spa and Wellness rituals conducted in a period of one month, three times per week. Each treatment was a temperature contrast procedure through a Parafango body thermo-application and a face cryo-gel application. The facial skin condition was assessed by an A-ONE apparatus an automatic skin diagnostic analyzer. Results: A significant improvement in the skin elasticity in the three studied age groups was observed after the procedures. This indicator increased 3.75 units $(9.93 \%)$ in the $35-44$ age group, 3.5 units $(11.36 \%)$ in the $45-54$ age-group and 1.80 units $(8.22 \%)$ in the observed individuals from 55-65 age-group. At the end of a treatment, the increase in all three age groups was statistically significant $(\mathrm{p}<0.05)$. Skin elasticity assessment was significantly lower for all three age-groups before the procedures, compared to the established standards. After the applied procedures, the skin elasticity was approaching the established standard (the first age group exceeded the standard, the second approached the standard and the third was slightly below the standard). Conclusion: The study reveals that the complex effects of hot and cold procedures result in improved skin elasticity.
\end{abstract}

Keywords: Spa, Wellness, cryotherapy, thermotherapy, skin elasticity

\section{Introduction}

Since ancient times the beneficial influence of the natural methods and resources on health and beauty, including the complex effects of the thermal 
and cold procedures, has been known. The authors in their studies confirm that the contrasting procedures' impact on the skin aesthetic vision is undeniable. These procedures are a part of the modern Spa \& Wellness concept, which strives for a healthy lifestyle and achieving "Well-Being" - good health and good spirit (Baumann, 2007; Cholewka et al., 2011; Clijsen et al., 2008; Dawes, 2013).

The temperature contrast results in a significant improvement in the condition of the entire organism, including the skin as an organ. These effects are due to the blood circulation improvement, activation of the cellular metabolism, balancing of the endocrine functions of the glands, stimulation of the immune system and controlling stress and fatigue. Moreover, these beneficial effects are related to the improvement of the skin aesthetic vision. The application of temperature-contrast procedures causes a skin-vascular reaction, and this in turn leads to neovascularization, improving the skin microcirculation, and stimulating the dermal fibroblasts function. It also activates the elastin, collagen and glucosaminoglucan-hyaluronic acid synthesis which are responsible for the skin condition, and more specifically its elasticity (Baumann, 2007; Cholewka et al., 2011; Escoffier et al., 1989; Shin et al., 2005). Improved skin elasticity results in a natural skin aesthetic vision. The objective assessment of the aesthetic skin appearance is based on examination of various indicators, one of which is the skin elasticity.

\section{Purpose}

The present study aims to evaluate the complex effects of the thermal and cold procedures used in the modern Spa \& Wellness concept applied on skin elasticity, which is an integral part of the factors influencing on aesthetic skin vision.

\section{Material and Methods}

The subjects of this study were 60 women aged 35 to 65 years, divided into 20 individuals in three age groups (35-44; 45-54 and 55-65 years). They were selected on a voluntary principle, as an excluding criterion was a presence of diseases that are contraindicated for application of heat and cold procedures. The present study was conducted during the period of 2010-2013 in Dzhambazovski Center, Hotel Ambassador, Republic of Macedonia.

\section{Skin diagnostic methodology}

The skin condition of the individuals was evaluated by applying an AONE skin diagnostic apparatus, which measures the following parameters: elasticity, humidity, wrinkles, pigmentation, pores, etc. The assessment was conducted before and after the 12 procedures applied, included in the Aesthetic Spa \& Wellness Ritual. 
The A-ONE system applied in this study is a modern method for automatic skin diagnosis and it is characterized as a new generation of software solutions. To measure the elasticity parameter, the device software sets standard values - 40 units is a standard for the 35-44 age group, 35 units for the 45-54 age group, and 30 units for the 55-65 age group.

The diagnosis was performed on a clean body skin and face skin without cream and makeup. The results obtained were automatically compared to the established software standard, corresponding to the age and skin type. This allowed objective assessment of the skin elasticity parameter, applied during the Aesthetic Spa \& Wellness ritual.

\section{Methodology of the applied Aesthetic Spa \& Wellness ritual}

The tracked individuals were welcomed into a relaxing atmosphere; the methodology of the thermo-application on the body skin and cryoapplication on the face skin was carefully described in details. This conversation created a sense of well-being and trust in the specialist's professional approach. Aesthetic Spa \& Wellness ritual is always started with thermal application on the body skin, while simultaneously applying the cryoapplication of the facial skin. This sequence was repeated in all 12 procedures over a period of one month, three times per week.

\section{Methodology of a Parafango thermal-application on the body skin}

For the thermal procedures we used parafango-applications. Parafango is a mixture of paraffin and volcanic mud. Those applications were heated to $50^{\circ} \mathrm{C}$ and the resulting emulsion was poured onto a special pad. Parafango can be repeated multiple times. After each procedure, the packs were sterilized at $130{ }^{\circ} \mathrm{C}$. Parafango thermo-applications were placed on a bed covered with two $2 \mathrm{~m}$ x $2 \mathrm{~m}$ cotton sheets, and there was a nylon sheet between them. The client was undressed and lying down on her back during the thermoapplication, which in turn enveloped her whole body. The clients' backs were covered with a natural wool blanket, and the client was left in a favorable position for a period of 30 minutes. Then the she was unwrapped and her body was dried with a towel, in order to absorb the sweat. The client dressed immediately to keep the body warm.

\section{Methodology of a cryo-application on the facial skin}

A cryo-application on the face was simultaneously applied with the parafango thermo-application on the body. The individual's face was covered with cotton fabric, which followed the shape of the ice-gel applicator. Cryoapplications with ice gel (Rehamed Deutschland) were placed in plastic bags that follow the shape of the face with openings for the eyes and mouth. Cryoapplication's temperature was $-20^{\circ} \mathrm{C}$, which was maintained in a special cryo- 
camera. The cryo-applicator was applied on clean, facial skin, free of cream and make-up, three times within 30 minutes. Duration of cryotherapy treatment was applied at intervals - three minutes of cryotherapy then pause for seven minutes. After the treatment was complete, the cryo-applicator was removed and the skin was dried with a cloth.

Statistical methods: The hypothesis check was completed by the Student tcriterion and Fisher's F-criterion.

\section{Results}

The results of the study in terms of skin elasticity are presented in Table 1 and graphically illustrated in Fig. 1.

Table 1. Changes in the skin elasticity (mean value and standard deviation) in the three groups before and after procedures

\begin{tabular}{|c|c|c|c|c|c|c|c|c|c|}
\hline Groups & $\mathbf{X}_{1} \pm$ SD & $\mathrm{X}_{2} \pm \mathrm{SD}$ & $\begin{array}{c}\text { Difference } \\
\left(\mathbf{X}_{\mathbf{1}}-\mathbf{X}_{\mathbf{2}}\right)\end{array}$ & d\% & $\begin{array}{c}\text { Cohen's } \\
\text { d }\end{array}$ & $\mathbf{t}$ & $\mathbf{P}(\mathbf{t})$ & $\mathbf{F}$ & $\mathbf{P}(\mathbf{F})$ \\
\hline $\begin{array}{c}\text { 35-44 yrs. } \\
(n=20)\end{array}$ & $\begin{array}{c}37,75 \pm \\
1,92\end{array}$ & $41,40 \pm 2,35$ & 3,75 & 9,93 & 4,41 & 19,71 & 100 & & \\
\hline 45-54 & $30,80 \pm 2,44$ & $34,30 \pm 2,47$ & 3,50 & 11,36 & $\mathbf{6 , 8 2}$ & 30,51 & 100 & 1417,9 & 100 \\
\hline $\begin{array}{c}\text { yrs. }(n=20) \\
55-65 \text { yrs. } \\
(n=20)\end{array}$ & $21,60 \pm 3,44$ & $23,40 \pm 3,6$ & 1,80 & 8,33 & 4,39 & 19,62 & 100 & & \\
\hline
\end{tabular}

$\mathrm{n}$ - number of subjects; yrs. - years; $\mathrm{X}_{1} \pm \mathrm{SD}$ - mean value and standard deviation before procedures; $\mathrm{X}_{2} \pm \mathrm{SD}$ - mean value and standard deviation after procedures; P-significant difference compared with values before treatment for each group (Student t-test)

Before beginning the procedures, in the first age group surveyed (3544 years) the initial mean average of the elasticity index was $37.75 \pm 1.92$ units and increased to $41.40 \pm 2.35$ units at the end of the study. The achieved improvement of 3.75 units $(9.93 \%)$ is statistically significant $(\mathrm{t}=19.71, \mathrm{P}(\mathrm{t})$ $\approx 100.0$ ) and clinically significant (Cohens'd $=4.41)$. The initial mean average of the elasticity index in the second age group (45-54) had a value of $30.8 \pm 2.44$ units. After the completion of 12 procedures, the skin elasticity index increased with 3.5 units $(11.36 \%)$ and reached a mean value of $34.30 \pm 2.47$ units. The increase in elasticity index is statistically significant $(t=30.51, P$ $(\mathrm{t}) \approx 100.0)$ and practically significant $($ Cohens'd $=6.82$ ). In the third age group

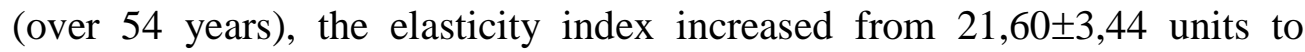
$23,40 \pm 3,60$ units, i.e. with 1.80 units $(8.33 \%)$ and also is statistically significant $(\mathrm{t}=19.62, \mathrm{P}(\mathrm{t}) \approx 100.0)$ and practically significant $($ Cohens'd $=$ 4.39). 
45

40

35

30

25

20

15

\section{Facial skin elasticity}

41.4

37.75

34.3

30.8

23.4

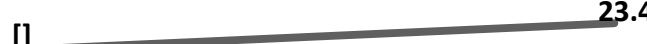

Fig. 1 Dynamics of the facial skin elasticity results in the individual age groups before and after procedures

The absolute increase of the results in the first two age groups is markedly improved (3.75 units and 3.50 units respectively). The improved elasticity index in the third age group is significantly less (1.80 units). Due to the natural influence of age on the aesthetic appearance of the skin, the comparison with the established standard in the diagnostic method applied in this study is more important.

The results between initial and final measurements are presented in Table 2 and in Fig. 2.

The established standard for the 35-44 age group is 40 units. The representatives of this age group were closest to a standard index values. Before staring the procedure, the average value of $37.75 \pm 19.2$ units was with 2.25 units lower than the standard, $(\mathrm{t})=5.25, \mathrm{P}(\mathrm{t})=100)$. After the procedure, the result was $41,40 \pm 2,35$ units, 1,40 units higher than the standard. This difference is statistically significant $(\mathrm{t})=2,85, \mathrm{P}(\mathrm{t}=99,00)$.

The established standard for the 45-54 age group is 35 units. Before starting the procedure, the measured value of the skin elasticity in this group was 30.80 units, the difference of -4.2 is statistically significant $(t)=7.69, P$ $(t=100)$. According to the final research results, the elasticity average value in the second measurement of 34.30 was with a difference of -0.70 units below the standard, and the difference is statistically unreliable $(t)=1,27, P(t=77,9)$, which means that the tracked individuals have reached the standard of their age level. 
Table 2. Comparison of the mean values and standard deviation of each age groups before and after procedures with the standard values for the skin elasticity according the age

\begin{tabular}{|c|c|c|c|c|c|c|}
\hline Groups & $\begin{array}{c}35-44 \\
\text { yrs. } \\
(n=20) \\
X_{1} \pm \text { SD }\end{array}$ & $\mathbf{X}_{2} \pm$ SD & $\begin{array}{c}\text { 45-54 yrs. } \\
(n=20)\end{array}$ & $\mathbf{X}_{2} \pm$ SD & $\begin{array}{c}\text { 55-65 yrs. } \\
(n=20)\end{array}$ & $\mathbf{X}_{2} \pm$ SD \\
\hline $\begin{array}{l}\text { Mean } \\
\text { values }\end{array}$ & $\begin{array}{l}37,75 \\
\pm 1,92\end{array}$ & $41,40 \pm 2,35$ & $30,80 \pm 2,44$ & $34,30 \pm 2,47$ & $21,60 \pm 3,44$ & $23,40 \pm 3,6$ \\
\hline $\begin{array}{l}\text { Standard } \\
\text { value }\end{array}$ & 40 & 40 & 35 & 35 & 30 & 30 \\
\hline $\begin{array}{c}\text { Difference } \\
\mathbf{t} \\
\mathbf{P}(\mathbf{t})\end{array}$ & $\begin{array}{l}-2,25 \\
5,25 \\
100\end{array}$ & $\begin{array}{l}1,40 \\
2,85 \\
99\end{array}$ & $\begin{array}{l}-4,20 \\
7,69 \\
100\end{array}$ & $\begin{array}{l}-0,70 \\
1,27 \\
77,9\end{array}$ & $\begin{array}{l}-8,40 \\
10,92 \\
100\end{array}$ & $\begin{array}{l}-6,60 \\
8,19 \\
100\end{array}$ \\
\hline
\end{tabular}

$\mathrm{n}$ - number of subjects; yrs. - years; $\mathrm{X}_{1} \pm \mathrm{SD}$ - mean value and standard deviation before procedures; $\mathrm{X}_{2} \pm \mathrm{SD}$ - mean value and standard deviation after procedures; Difference between standard value and mean values of the three groups before and after procedures; Psignificant difference compared with standard values before and after procedures for each group (Student t-test)

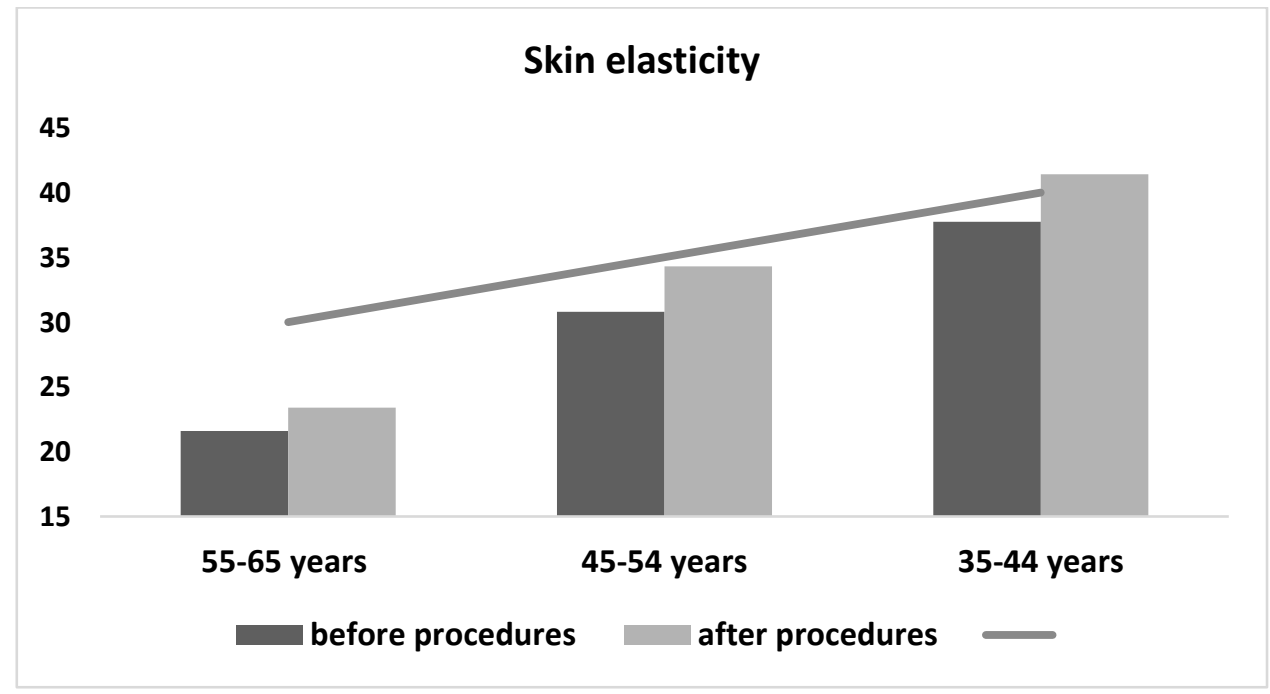

Fig. 2 Comparison of group average value with the standard in each measurement

The skin elasticity of the tracked persons in the third age group was in worse condition - over 54 years. The established standard for the age group is 30 units and before the procedure the mean average was 21.60 units. The difference from the standard of -8.40 is statistically significant $(t)=10.92, P$ $(t)=100$. After the applied procedure, the elasticity skin index was 23.40 units, the difference from the standard of -6.60 is again statistically significant $(t)=$ $8.19, \mathrm{P}(\mathrm{t})=100)$.

As a result of the conducted procedures, the skin elasticity increase was statistically significant, in all tracked persons $(\mathrm{F}=1417,9, \mathrm{P}(\mathrm{F}) \approx 100,00$. 


\section{Discussion}

Our findings suggested that the results obtained in regard to the skin elasticity showed significant improvement in all age groups, which also means a positive change in the aesthetic appearance of the skin.

The causes of aging skin and the reduction of its elasticity are numerous and depend on many factors. Aging skin is a part of the natural "mosaic aging". Researchers have shown that the cellular metabolism of the skin slows down, and the number of dermal fibroblasts decreases with age. As a result of these structural changes, the secretory function of dermal fibroblasts and the biosynthesis of elastin biosynthesis, collagen and hyaluronic acid reduce, which causes the loss of skin elasticity and natural, youthful looking skin (Baumann, 2007; Escoffier et al., 1989; Maznev et al., 2017; Shin et al., 2005).

The root cause of the skin aging process is the reduction of skin perfusion. In his research, Li L. tracked a group age of 20-74 years and proved that as age progresses, the capillary net density decreases by $40-70 \%$ (Li et al., 2006). This shows that skin rejuvenation processes are dependent on improving the blood circulation in the skin.

The effect of hot and cold applications on the skin in the tracked individuals can be explained by a number of physiological changes caused by the influence of these physical factors. One explanation is the occurring improvement of skin perfusion and its aesthetic vision. In a recent study, the authors demonstrated that parafango thermal applications increased blood perfusion rate in the skin from 23.2 to 197 p.u. and this parameter remained elevated during the parafango thermal application and decreased slowly to baseline after the applied therapy (Clijsen et al., 2008).

Another effect of the thermal procedures is the activation of dermal fibroblasts and increase of structural proteins secretion responsible for the skin condition. Société de Recherche GREDECO, in collaboration with researchers at Pitié-Salpetriere Hôpital in Paris, conducted a clinical study on skin biopsies aiming at skin rejuvenation by heating. The results obtained showed the production of new collagen from the dermis (more than 40\%) in the dermal skin biopsies of the skin treated with thermal procedures as compared to the non-thermal skin biopsy control samples (Lazar, 2008). This confirms that the heat activates the dermal fibroblasts and stimulates their secretory function.

The conducted studies have confirmed that the application of cryotherapy also reduces signs of skin aging. The cryotherapy stimulates blood circulation in the skin and activates all skin layers and structures, resulting in a natural and younger appearance (Cholewka et al., 2011).

In his study, Guan, $X$. examined the effects of two different temperature influences $\left(37^{\circ} \mathrm{C}\right.$ and $-20{ }^{\circ} \mathrm{C}$ ) on human fibroblast cell cultures. The results were better at a temperature of $-20{ }^{\circ} \mathrm{C}$ as compared to the effect 
obtained at $37^{\circ} \mathrm{C}$. The shock cooling maintains the vitality of the fibroblast cell, activates cellular proliferation and differentiation, and stimulates its function (Guan et al., 2007). The data obtained confirms that cryotherapy is a powerful method for revitalizing and stimulating of the dermal structures.

The mentioned studies show that both thermotherapy and cryotherapy have a beneficial effect on the skin rejuvenation process. In addition, the authors have found that the complex effects of cryo- and thermotherapy create an intensive improvement in blood circulation, which in turn delivers blood to all skin structures. New capillaries are being created that supply blood to deficient areas, and therefore connective tissue cells are stimulated, in particular dermal fibroblasts (Baumann, 2007; Escoffier et al., 1989; Shin et al., 2005). The physiological changes, occurring under influence of temperature contrast on the skin, can be explained by a skin-vascular reaction in which the skin perfusion increases (Koleva, 2010; Kostadinov \& Kraev, 1987; Tasheva, 2007). This, in turn, stimulates the dermal fibroblasts. It leads to elastin biosynthesis, and collagen and glycosaminoglycan-hyaluronic acid increase, which are responsible for the general skin condition and elasticity (Samuel et al., 1987).

The aforementioned changes in skin microcirculation, the activation of dermal fibroblasts, and possibly other effects result in increasing of skin elasticity, which is an essential element of the aesthetic appearance of the skin (Maznev et al., 2017).

The data obtained in our research shows that during the application of Aesthetic Spa \& Wellness ritual there is a significant increase in skin elasticity in all age groups. When comparing to the established standard, before starting the procedures, in all groups the results were lower than the standard. As a result of the beneficial effect of the applied therapy, the representatives of the first age group have had skin elasticity higher than the standard. The second age group managed to reach the established age- standard. However, the third age group did not reach the standard, despite the observed positive effect of the procedures.

A better effect achieved in younger individuals as compared to older individuals can be explained by the fact that the physiological potential for activating skin rejuvenation mechanisms is greater. In younger individuals, the cellular metabolism of the skin is faster and the dermal fibroblasts are greater in number. The skin vascularization is also better, which is associated with better skin perfusion, more intensive dermal fibroblasts function, and synthesis of structural proteins responsible for the skin condition, specifically elasticity. The positive effect of the applied procedures is visible in the other two age groups as well, however it is less pronounced than in the first age group. 


\section{Conclusion}

At the conclusion of the study, we established that the complex effects of the thermal and cold procedures, applied in the aesthetic Spa and Wellness ritual, are associated with a number of beneficial physiological changes that have a positive influence on the skin elasticity in all observed participants. The intensity of the skin elasticity is the most pronounced in the first tracked age group and decreases with age.

\section{References:}

1. Anchevski, A., Gotsev, G., et al. (2005), Dermatovenereology, Skopje, Culture.

2. Baumann, L. (2007), Skin ageing and its treatment. J Pathol, Vol. 211 No. 2, pp.241-51.

3. Cholewka, A., Stanek, A., Sieroń, A., Drzazga, Z. (2012), Thermography study of skin response due to whole-body cryotherapy. Skin Research and Technology Vol. 211 No. 2, pp. 180-187

4. Clijsen, R., et al. (2008), Changes of skin characteristics during and after local Parafango therapy as used in physiotherapy $\underline{\operatorname{Skin} \operatorname{Res}}$ Technol, $\quad$ Vol. 14 No. 2, pp. 237-42. https://www.ncbi.nlm.nih.gov/pubmed/18412568

5. Dawes, J. (2013), Hydrotherapy (ISPE Handbook - Design \& Planning of Swimming Pools), UK, London, Columnes

6. Escoffier, C., de Rigal, J., Rochefort, A., et al. (1989), Age-related mechanical properties of human skin: an in vivo study. $J$ Invest Dermatol, Vol. 93 No. 3, ,pp.81-93

7. Guan, X., at al. (2007), The effect of different thawing temperatures on morphology of collagen metabolism of -20 degrets dealt normal human fibroblast. Medline, cryobiology, Vol. 25, No. 1, pp.52-59. http://europepmc.org/abstract/med/17617396 .

8. Koleva, I. (2010), Fundamentals of Physical Medicine, Physiotherapy and Rehabilitation (including Ergotherapy and Medical Spa) - Part I. Sofia, Medicine and Physical education

9. Kostadinov, D., Kraev, T. (1987), Physical Therapy. Sofia, Medicine and Physical education

10. Lazar, G. (2008), Évaluation du dispositif de radiofréquence tripolaire Regen $^{\mathrm{TM}}$ en utilisant un modèle expérimental de peau humaine". Les Nouvelles Dermatologiques, Vol.77 No.1, pp.65-67.

11. Li, L., Mac-Mary, S., Sainthillier, J., Nouveau, S., de Lacharriere, O., Humbert, P. (2006), Age-related changes of the cutaneous microcirculation in vivo. Gerontology, Vol.52 No.3, pp.81-87.

12. Maznev, I., Izov, N., Nikolova, M., Dimitrova, A., Grigorova-Petrova, K. (2017), Physical therapy and swimming influence on female type 
adipose deposition and cellulite. Journal of Applied Sports Sciences, No.1, pp. 58-62

13. Samuel, L., Moschella, M, Harry, J., Hurley, M. (1992), Dermatology. New Delhi, India, Harcourt Publishers Ltd,

14. Shin, M., Rhie, G., Park, C., et al. (2005), Modulation of collagen metabolism by the topical application of dehydroepiandrosterone to human skin. J Invest Dermatol, Vol.124 No.32 pp.315-23

15. Tasheva, R. (2007), SPA\&wellness - the essence and application. Medicine and sport, Vol.1, pp.16-20. 